\title{
Chapter 12 \\ Reciprocal Student-Teacher Feedback: Effects on Perceived Quality of Cooperation and Teacher Health
}

\author{
Jan-Erik Schmidt and Caterina Gawrilow
}

\begin{abstract}
High lesson quality in schools is, in addition to other factors, the result of good cooperation between teachers and students. The long history of research on offer-use models of lesson quality and student-teacher relationships documents this interaction. Feedback focused on expressing the quality of cooperation can lead to higher quality of cooperation. The fact that feedback is reciprocal, from teacher to student and vice versa, helps to avoid effects of perceived injustice and rejections of feedback which otherwise are severe obstacles to the efficient use of feedback. High-frequency applications of feedback allow for the timely detection of (positive and negative) critical fluctuations of cooperation between individuals and groups and for the monitoring of processes of adaptation, as shown in other areas of applied psychology. This chapter describes the theoretical parameters of such a feedback method for students and teachers, and outlines results of an empirical study on the effects of the reciprocal method on (1) perceived quality of cooperation and (2) teacher health. Results show that, subsequent to a three-month period of reciprocal feedback, the quality of cooperation as perceived by both students and their teachers increases significantly and teacher health scores improve significantly. Reciprocal feedback techniques should be considered in teacher education and teacher training as a way to help teachers to initiate processes of improvement of lesson quality.
\end{abstract}

Keywords Feedback $\cdot$ Student-teacher interaction $\cdot$ Cooperation $\cdot$ Co-regulation • RCT

\footnotetext{
J.-E. Schmidt $(\bowtie)$

Center for School-Quality and Teacher Education, Tübingen, Germany

e-mail: jan-erik.schmidt@zsl.kv.bwl.de

C. Gawrilow

Department of Psychology, University of Tübingen, Tübingen, Germany

e-mail: caterina.gawrilow@uni-tuebingen.de
} 


\section{Introduction}

One of the most general definitions of feedback states that feedback is "information about the gap between the actual level and the reference level of a system" (Ramaprasad, 1983, p. 4). Going beyond this general definition, there is a need for a structured overview of the many different forms of feedback which have been suggested for fostering development in schools. For this, the five main characteristics of each kind of feedback should be made clear: (a) the source of feedback, (b) the recipient, (c) the topic, (d) the method, and (e) the frequency of the feedback (Hattie \& Wollenschläger, 2014; Kluger \& DeNisi, 1996; Mikula et al., 1990).

The most common form of feedback in the educational field is when a teacher provides feedback to a student about academic results or about their techniques of problem-solving and self-regulation in school (Hattie \& Timperley, 2007). Giving feedback in the other direction - from students to teachers - seems to be an important aspect too (Hattie, 2009). Furthermore, providing feedback in both directions simultaneously could be even more powerful. This is because the teacher and student are both actors in the learning in school and both benefit from information about the transaction they create. The questions of (a) what contents and topics teachers and students should receive feedback on and (b) what kind of information is reliable are matters of intense research and are addressed in several chapters of this book, for example, Chap. 3 (Röhl and Rollett), Chap. 4 (Bijlsma), Chap. 5 (van der Lans), and Chap. 7 (Göllner et al.). This chapter refers to one specific feedback topic - the quality of cooperation between teachers and students as a class-and provides information about the views of students about their teacher and vice versa. More specifically, we also refer to a certain type of feedback-reciprocal feedback-where teacher and students send and receive feedback at the same time. Thus, the interaction between teacher and students and the dynamics of interaction can be addressed via a feedback process. The rationale and theoretical background of this kind of feedback is explained in the first part of the chapter, followed by a description of the research method used in our study. The third part presents results of a first empirical study on the effects of this form of reciprocal feedback.

\subsection{Feedback Frequency}

A question which - to the best of our knowledge - has so far drawn little attention from researchers is: How frequently should reciprocal feedback be provided in order to trigger practical consequences? Some research on frequency has been done in occupational settings (Ilgen et al., 1979; Kluger \& DeNisi, 1996; Kuvaas et al., 2017; Park et al., 2019) and on the feedback from teachers to students (Guo \& Wei, 2019; Pinter et al., 2015; Tamara et al., 2004). Also, strong support for the use of highfrequency feedback has been documented in the field of psychotherapy (Schiepek et al., 2016). However, there are no empirical studies addressing the effectiveness of 
feedback frequency in the student-to-teacher direction. Furthermore, although dyadic regulation processes have already been investigated in some areas of psychology, there is no such research on the association of self-regulation and dyadic regulation processes in classroom scenarios.

The feedback introduced in this chapter is applied weekly and has been shown to be easily manageable (Schmidt, 2018). A higher frequency-e.g., daily-may be even more effective, as primacy and recency effects would be reduced. On the other hand, this would also be more difficult to realize. Weekly application thus seems a good compromise to foster co-regulation processes in the classroom between students and teachers-frequent and timely enough to be both effective and still manageable.

\subsection{Interpersonal Facets of Feedback}

Interpersonal facets of feedback such as "credibility" and "sender intentions" as perceived by the recipient play an important role in the acceptance and use of feedback (Umlauft \& Dalbert, 2012). Those interpersonal facets can determine whether feedback information is well received and elaborated upon or is rejected. Important characteristics of persons giving feedback are their perception of being legitimated, being seen as credible, and by their motivation and intention to support the person receiving feedback. Feedback givers must also display the ability to interact in a friendly manner so that feedback information is likely to be elaborated upon. Depending on the recipient's self-esteem and appraisal strategies, feedback carries the risk of causing negative emotions and outcomes such as lowered self-esteem and reduced effort (Leary \& Terry, 2012). Feedback can be potentially perceived as unjust, and such a perception of injustice causes a variety of unwanted results, including (1) rejection of the feedback, (2) feelings of being excluded from a group, and (3) higher delinquent behavior (Mikula et al., 1990; Umlauft \& Dalbert, 2012). All reported findings above focus on feedback given from instructors to their students. These mentioned risks can, however, be potentially reduced if students are involved and asked to give feedback from their perspective. When students are asked to provide feedback on cooperation with their teacher, they are implicitly addressed as competent professional partners and thus highly validated. Additionally, as teachers and students are asked to provide feedback, it is implicitly acknowledged that the views of students and teachers can differ without one being wrong or right, and that both views must be considered. Thus, perceptions of injustice could be avoided. Therefore, we see strong reasons for considering a reciprocal construction within feedback on aspects of lesson quality. 


\subsection{Cooperation-A Basic Ingredient for Lesson Quality}

Cooperation between teachers and students addresses the fundamental characteristic of lesson quality as a transactional phenomenon, meaning that both, teachers and students, have to contribute certain activities to create a lesson. Evidence implies that feedback given from students to teachers concerning student perceptions of lesson quality can contribute to teaching effectiveness (Bill \& Melinda Gates Foundation, 2012; Helmke et al., 2009; Pianta et al., 2008; Raudenbush \& Jean, 2015). Still missing in this base of research is a focus on the transactional and complex character of teaching and learning (Brophy \& Good, 1984; Pianta \& Hamre, 2009; Pianta et al., 2003). Helmke introduces his Angebots-Nutzungs-Modell (Offer-Uses Model of Lesson Quality) by stating that "Good lessons are a coproduction between teachers and students" (Helmke, 2007, p. 63), suggesting that lesson quality is the result of an offer made by the teacher-as well as the result of acceptance and use of this offer by students. Moreover, the subsequent offers by the teacher are influenced by the use which students may have made of former offers. This view of teaching processes is characterized by reciprocity, irreversibility, and non-linearity as characteristics of living systems (Orsucci, 2006; Schiepek, 2009).

In other areas of psychology (as compared to educational and school psychology) the focus has changed from mere (self-) regulatory to dyadic (co-)regulation processes. Importantly, in social and health psychology, the strong claim is made that being accepted by a group and being part of a group (Forgas \& Fiedler, 2020) leads to better health and a longer life. Hence, there is consistent empirical evidence that social and group relationships are protective factors for psychological and physiological health: Individuals lacking social ties are physically and mentally less healthy and more likely to die prematurely than socially integrated individuals (House et al., 1988). Transferring these social relationship results to educational and school psychology means that students and teachers who (a) work together in a cooperative and friendly manner, (b) have a productive feedback culture, and (c) feel part of the social group within the classroom and/or school, should report better well-being and maybe also better academic results. However, despite results which describe a good teacher-child relationship as a predictive factor for favorable short- and long-term outcomes in students (Hamre \& Pianta, 2006), there is less research on co-regulation processes in educational contexts.

\subsubsection{Cooperation and Student-Teacher Interaction}

The importance of student-teacher interaction for teaching and learning has been shown across many dimensions (Hamre \& Pianta, 2006; Seidel \& Shavelson, 2007; Verschueren \& Koomen, 2012). Students who report better relationships with their 
teacher have higher academic success, as well as better social and emotional competences. In particular, "at risk" students benefit from a good student-teacher relationship (Baker, 1999; Birch \& Ladd, 1998; Cheon \& Reeve, 2015; Eccles \& Roeser, 2011; Jennings \& Greenberg, 2009; Raufelder et al., 2016; Wentzel, 2009). Specifically, student-teacher relationships include the domains of (1) organizational support, (2) academic support, and (3) social support (Eccles \& Roeser, 2011; Pianta \& Hamre, 2009). From a transactional point of view, such interactional support can be seen as the result of a successful process of cooperation between the teacher and their students. According to Axelrod (1984), cooperation is the willingness to abstain from maximum personal gain in favor of a common good including the willingness to seek compromises. The common good in this case can be defined as "lesson quality", for which both students and teachers are interested in over a long-term perspective. Contributions to lesson quality by students are behaviors such as: (1) taking out their book in a good pace, (2) working silently in order not to disturb others, or (3) raising a question when feeling blocked. These behaviors are potentially hindered by students' short-term interests in more personal gains. Example behaviors of short-term interests which may override interest in the common good of lesson quality can be: (1) making contact to a classmate, (2) taking a rest, (3) avoiding being judged by others when asking questions, or (4) low impulse control such as wishing acknowledgment for a good joke. The concept of cooperation serves two more benefits. Firstly, neither students nor teachers feel personally judged, since cooperation addresses an interpersonal rather than an intra-individual facet of lesson quality. Thus, feelings of humiliation are avoided - so helping to prevent withdrawal or even revenge (Furman $\&$ Ahola, 2006). Furthermore, by viewing both teachers and students as contributors to classroom success, this serves students' need for justice as described above. Secondly, asking students how they evaluate the cooperation between themselves and their teacher implicitly conveys the message that teachers see students as capable of contributing and see their contribution as important, which supports students' needs of self-efficacy and self-determination (Ryan \& Deci, 2009). Feedback which focuses on the cooperation between students and their teacher should help the contributors reflect on their cooperation and improve it in a threefold manner: (a) by helping students to bring up ideas for the improvement of lesson quality which are from their perspective relevant, (b) by creating a situation in which teachers can learn about how students perceive lessons, tasks, and explanations and thereby receive insight into the effects of their teaching, and (c) by improving social support when listening to each other and implementing ideas developed together. 


\section{A Feedback Technique for Iterative Feedback About Student-Teacher Cooperation}

In order to implement reciprocal feedback as described above, we developed and tested a method which focusses on the quality of cooperation between a teacher and their class as perceived by both parties. Students and teachers give their feedback weekly at the end of the last school lesson. To do so, they answer the core question of the feedback technique, "How do you evaluate the cooperation between you as a class and your teacher during the last week?", by throwing a coin into a box with five labeled compartments (very good, rather good, average, rather poor, and very poor) for possible answers. The teacher answers the equivalent question, "How do you judge the cooperation between you and your class during the last week?", by throwing a different colored coin into the box. Results of each feedback session-the distribution of the students' answers and the teachers' answers-were displayed on a classroom poster at the beginning of the first lesson of the next week, and the results of all weeks remained visible during the whole feedback period. Teachers and students were invited to discuss the results of the feedback each week following a solutionfocused protocol in which the teachers had been trained. Thereby, the classes are guided to discuss: characteristics of weeks with higher quality of cooperation ("Why did you assess this week as having better cooperation than this other one?"); which teacher activities and which student activities contributed to good lesson quality ("What did I do to help us cooperate in this week? What did you do?"); and what could each side do to further contribute to lesson quality ("What can I do to improve our cooperation? What could you do to improve our cooperation?").

\section{Own Empirical Study}

A first controlled trial study was conducted in the field of teachers' health. We specifically investigated the effects of the reciprocal feedback method on teacher health. The rationale behind this was that the reciprocal technique could help teachers take the transactional character of lesson quality more into account by using information the students give, which would in turn foster cooperative activities which the students can participate in. The first research question was: Does teacher health improve during or after the feedback period?

To ensure an appropriate application of the feedback method it is required that teachers share the underlying idea that quality of cooperation is a core ingredient of good lesson quality and that students can contribute important information to the improvement of cooperation. Therefore, we also measured teachers' Resource Orientation in respect to their students. Resource Orientation is the assumption that students have the ability to assess lesson quality and to develop ideas for the improvement of cooperation. Our hypothesis was that the experience of iterative feedback on cooperation should lead to a higher Resource Orientation among the teachers 
through the experience of better cooperation, and thus reduce occupational stress which arises when teachers try to manage the class by relying primarily on their own activities. The second research question was: Does the perceived quality of cooperation as assessed by the students and by the teachers improve during the feedback period of three months?

\subsection{Procedure}

The sample consisted of 45 teachers from southern German mid-level schools and one of their classes between 6 and 9th grade (1022 students).

Each of the 45 teachers chose one of their classes in which they taught at least three lessons a week, and asked students to participate in the study. Teachers were randomly assigned to a treatment group $(n=23)$ or a waiting control group $(n=22)$. Resource Orientation and Teacher Health were assessed in the treatment and waiting control groups at three points of time $(T 0, T 1, T 2)$ with 12 -week intervals between each time point. After students and their parents gave written consent, the first measurement (T0) took place. Subsequently, teachers of the treatment group received a one-day training for the feedback method and a group supervision session after four weeks. Teachers of the waiting control group received their training after $T 2$. Immediately after the training, teachers and students in the treatment group applied the reciprocal feedback technique in their classes once a week for a consecutive period of 10 weeks. The supervision sessions during the feedback period were held in order to support teachers' use of the student feedback, helping them to understand the students' needs and how to lead solution-focused class talks, so that specific actions in the classroom could be derived from the feedback. For a more detailed description of the process of recruitment, random assignment, and data analysis see Schmidt (2018).

\subsection{Measures}

Teacher health was assessed with the General Health Questionnaire (GHQ-12) (Goldberg, 1992). The GHQ-12 is a frequently used worldwide screening instrument for detecting mental health problems. It assesses the inability to carry out one's normal healthy functions and the appearance of new phenomena of a distressing nature. The GHQ-12 asks about mental health issues during the last two weeks in comparison to the usual status of the participants. The questions include, for example, "Have you recently been feeling sad and gloomy?" Answers are coded on a four-point scale labeled e.g., less than usual, no more than usual, rather more than usual, much more than usual. Higher values indicate a higher problem level. The internal consistency of the GHQ-12 has been reported in a range of studies using Cronbach's alpha with correlations between .77 and .93 . 
To examine teachers' Resource Orientation, a scale called Resource Orientation Scale (ROS) was developed. The ROS consists of 12 items asking teachers how far they agree that (a) students are able to assess teacher-class cooperation and lesson quality (e.g., "My students can assess if they receive good individual support"), (b) students have useful ideas for the improvement of teacher-class cooperation and lesson quality ("My students have good ideas about what kind of support they need"), and (c) if the teacher actually uses the knowledge of students to improve lesson quality ("I use students' ideas on how to make tasks activating"). To quantify the extent of approval of the statements, answers were given on a four-point scale ranging from 1 (not true) to 4 (true). The measure's internal consistency was acceptable across time with Cronbach's alpha ranging $\alpha=.82$ at $T 0 ; \alpha=.87$ at $T 1 ; \alpha=.89$ at $T 2$.

The perceived quality of cooperation was gathered by comparing the feedback of students and teachers at the beginning of the feedback process $(T 1)$ and at the end of the process $(T 2)$. Therefore, results of the first three weeks and results of the last three weeks of the period were averaged.

\subsection{Results}

To assess the effects of the training, treatment and control groups were compared with respect to changes of the outcome variables from $T 0$ to $T 1$ and from $T 0$ to $T 2$, using regression analysis (Table 1). Therefore, outcome variables were $z$-standardized to $T 0$ means. Teachers' Resource Orientation increased significantly from $T 0$ to $T 1$ and teacher stress scores decreased significantly from $T 0$ to $T 2$, as reported in Tables 2 and 3, respectively. The patterns of changes of the Resource Orientation Scores (ROS) and teacher health (GHQ-12) scores in treatment and control group over all three points of measurement are displayed in Fig. 1.

To assess changes in the perceived quality of cooperation, $T$-Tests for dependent samples have been applied. Perceived Quality of Cooperation as assessed by teachers and by students increased significantly during the three-month feedback period with

Table 1 Unstandardized scores for resource orientation and teacher health outcomes at all measurement points

\begin{tabular}{|c|c|c|c|c|c|c|c|}
\hline \multirow[t]{2}{*}{ Scales } & & \multicolumn{2}{|c|}{$\begin{array}{l}T_{0} \\
N_{\text {treatment }}=23 \\
N_{\text {control }}=20\end{array}$} & \multicolumn{2}{|c|}{$\begin{array}{l}T_{1} \\
N_{\text {treatment }}=23 \\
N_{\text {control }}=21\end{array}$} & \multicolumn{2}{|c|}{$\begin{array}{l}T_{2} \\
N_{\text {treatment }}=21 \\
N_{\text {control }}=20\end{array}$} \\
\hline & & $M$ & $S D$ & $M$ & $S D$ & $M$ & $S D$ \\
\hline \multirow[t]{2}{*}{ ROS } & Treatment & 2.73 & .39 & 3.02 & .39 & 2.90 & .44 \\
\hline & Control & 2.68 & .40 & 2.68 & .46 & 2.72 & .48 \\
\hline \multirow[t]{2}{*}{ GHQ-12 } & Treatment & 1.93 & .43 & 1.80 & .38 & 1.66 & .29 \\
\hline & Control & 1.85 & .36 & 1.89 & .32 & 1.89 & .45 \\
\hline
\end{tabular}

Note $\mathrm{ROS}=$ Resource Orientation Scale; GHQ-12 = General Health Questionnaire 
Table 2 Regression analysis: treatment effects at $T 1$

\begin{tabular}{|c|c|c|c|c|c|c|}
\hline & \multicolumn{3}{|l|}{ ROS } & \multicolumn{3}{|l|}{ GHQ-12 } \\
\hline & $b$ & $(S E)$ & $p$ & $b$ & $(S E)$ & $p$ \\
\hline$T_{0}$ & $.610 * * *$ & $(.139)$ & $<.001$ & $.563 * * *$ & $(.215)$ & $<.001$ \\
\hline Treatment & $.286 *$ & $(.107)$ & .011 & -.119 & $(.087)$ & .180 \\
\hline$F$ & 13,827 & & & 13,278 & & \\
\hline$p$ & $<.001$ & & & $<.001$ & & \\
\hline$R^{2}$ & .415 & & & .399 & & \\
\hline
\end{tabular}

Note $\mathrm{ROS}=$ Resource Orientation Scale; GHQ-12 = General Health Questionnaire $*<.05, * * *<.001$

Table 3 Regression analysis: treatment effects at $T 2$

\begin{tabular}{|c|c|c|c|c|c|c|}
\hline & \multicolumn{3}{|l|}{ ROS } & \multicolumn{3}{|l|}{ GHQ-12 } \\
\hline & $b$ & $(S E)$ & $p$ & $b$ & $(S E)$ & $p$ \\
\hline$T_{0}$ & $.723 * * *$ & $(.148)$ & $<.001$ & $.734 * * *$ & $(.137)$ & $<.001$ \\
\hline Treatment & .079 & $(.117)$ & .502 & $-.206^{*}$ & $(.091)$ & .029 \\
\hline$F$ & 12,691 & & & 17,023 & & \\
\hline$p$ & $<.001$ & & & $<.001$ & & \\
\hline$R^{2}$ & .420 & & & .479 & & \\
\hline
\end{tabular}

Note $\mathrm{ROS}=$ Resource Orientation Scale; GHQ-12 = General Health Questionnaire $*<.05, * * *<.001$

$t(16)=4,24 ; p=.001 ; d=1,12$ for the students' view and $t(15)=3.90 ; p=.001$; $d=1.30$ for the teachers' view. Descriptive results for all classes of the treatment group can be seen in Fig. 2.

\section{Discussion}

Choosing quality of cooperation as a topic of feedback between students and their teachers and then applying reciprocal feedback repeatedly in a weekly frequency seems to be a promising approach for initiating improvement of lesson quality. Improvement in the perceived quality of cooperation from both the students' point of view and the teacher's point of view has been shown. Moreover, providing feedback about the perceived quality of cooperation to classes and inviting students to discuss cooperation in order to facilitate high lesson quality yielded improvements in teacher health. Furthermore, using such feedback for discussions between students and their teacher addresses a core process of lesson quality, since it fosters the effective use of feedback by addressing teachers and students in their role as cooperative partners. 

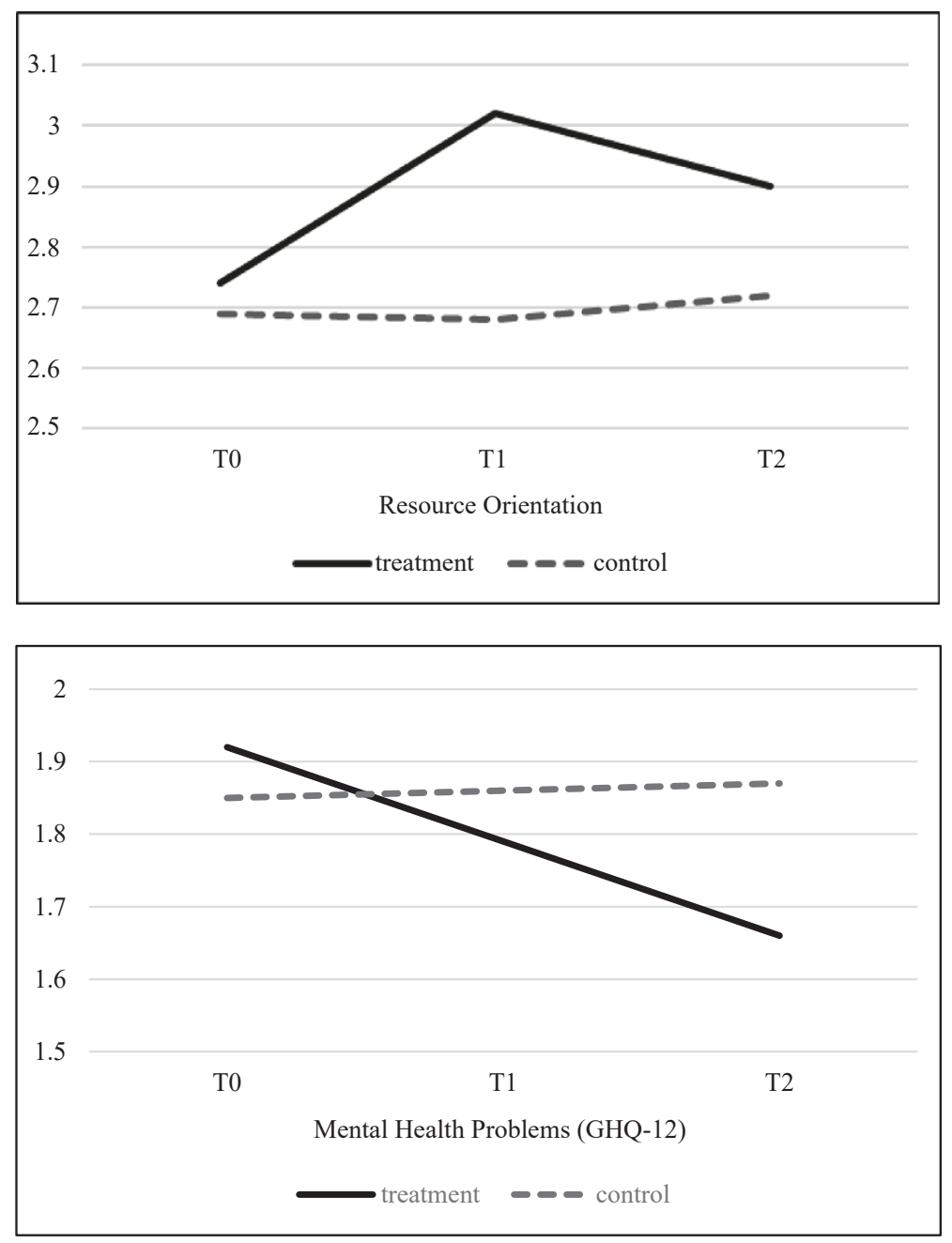

Fig. 1 Resource Orientation Scores (ROS) and teacher health (GHQ-12) scores in treatment and control group

This empirical evidence should encourage further research, as there are several limitations of the study. Firstly, the choice of classes by their teachers was deliberated. Teachers pointed out that they chose classes in which (a) improvement of cooperation between teacher and class is needed from their perspective and (b) they were confident that the group of students would be capable of using the method effectively in terms of the social relations among the students. Conflicts and a poor social climate among the students may be an obstacle to such feedback or might have to be addressed first. Secondly, future research should investigate effects of the suggested kind of feedback on other lesson quality measures than the perceived 

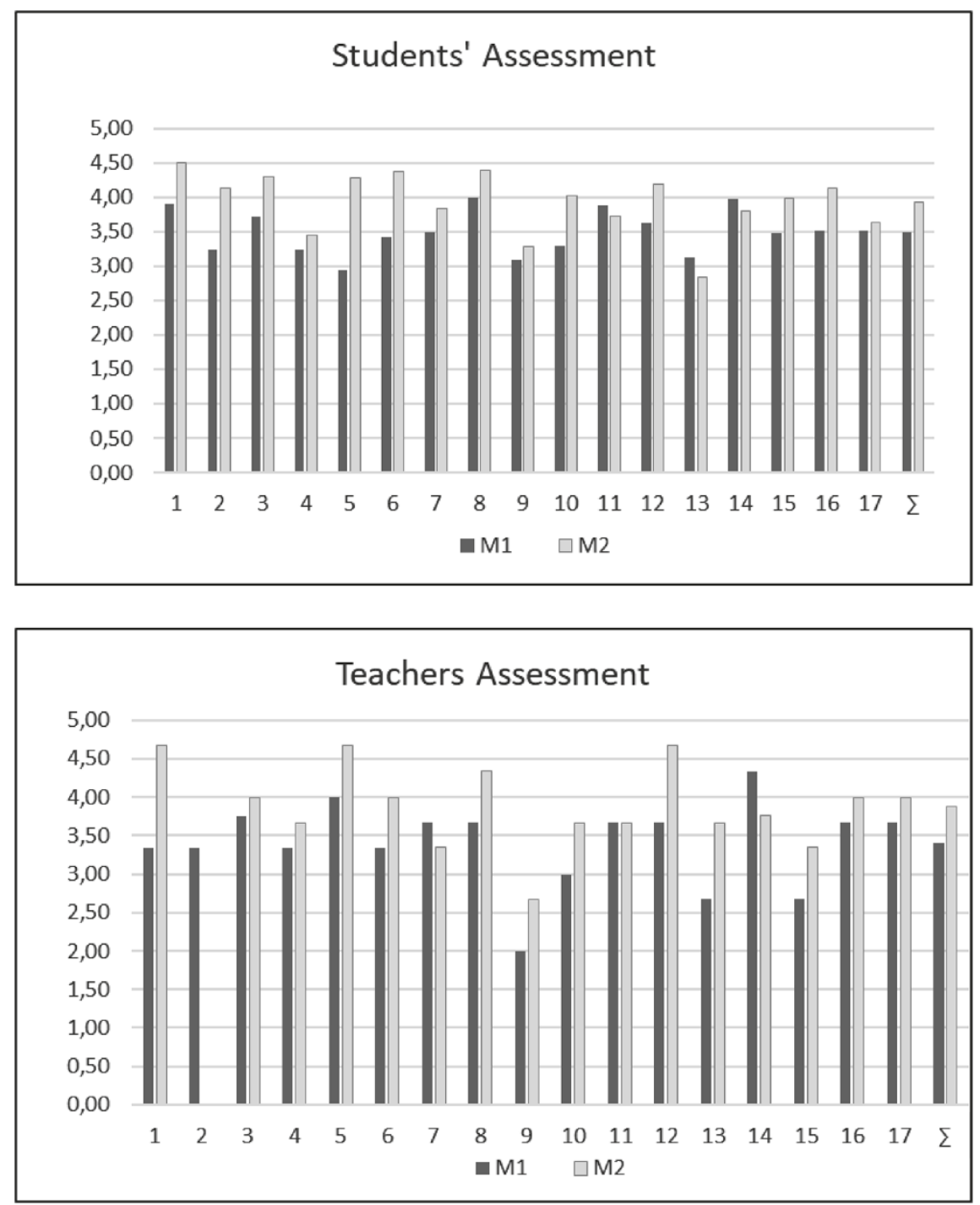

Fig. 2 Perceived quality of cooperation in each class (Note $M 1=$ average of first three weeks of feedback; $M 2$ = average of last three weeks of feedback. Due to technical barriers, not all classes provided data for all weeks of the feedback)

quality of cooperation; such measures could include time on task, cognitive activation, or emotional support, as assessed by students or external observers. We would tentatively suggest that improvement in those measures may well be as a result of improvements in cooperation between teachers and their students. Thirdly, the applied feedback technique includes several characteristics which should be further 
investigated. For example, the high-frequency application of feedback could possibly be tested with other feedback topics or methods. As things can develop fast in living systems, real-time data concerning the state of a system are crucial for understanding and adapting to particular situations. The reciprocal approach-inviting students and teachers to give feedback at the same time on the same topic — can be applied to other feedback topics. Lastly, the hypothesis that the type of feedback studied here fosters student-teacher relationships should be investigated more thoroughly.

In addition, further studies are needed which examine long-term effects of the regular use of iterative and reciprocal feedback on student-teacher relationships, teacher health, and students' academic results. Moreover, the idea that students can be viewed as partners in cooperation to improve lesson quality and that they can provide useful information to the process of cooperation should play a role in teacher education and teacher training-here teachers would develop an attitude and learn techniques to continuously strive for high lesson quality.

\section{References}

Axelrod, R. M. (1984). The evolution of cooperation. Basic Books.

Baker, J. A. (1999). Teacher-student interaction in urban at-risk classrooms: Differential behavior, relationship quality, and student satisfaction with school. Elementary School Journal, 100(1), 57-70. https://doi.org/10.1086/461943.

Bill and Melinda Gates Foundation. (2012). Gathering feedback for teaching: Combining highquality observations with student surveys and achievement gains. Policy and Practice Summary. MET Project. Bill \& Melinda Gates Foundation.

Birch, S. H., \& Ladd, G. W. (1998). Children's interpersonal behaviors and the teacher-child relationship. Developmental Psychology, 34(5), 934-946. https://doi.org/10.1037/0012-1649.34. 5.934 .

Brophy, J. E., \& Good, T. L. (1984). Teacher behavior and student achievement (Occasional Paper No. 73). Michigan State Univ, East Lansing Inst for Research on Teaching.

Cheon, S. H., \& Reeve, J. (2015). A classroom-based intervention to help teachers decrease students' amotivation. Contemporary Educational Psychology, 40, 99-111. https://doi.org/10.1016/j.ced psych.2014.06.004.

Eccles, J. S., \& Roeser, R. W. (2011). School and community influences on human development. In M. E. Lamb, M. H. Bornstein, M. E. Lamb, \& M. H. Bornstein (Eds.), Social and personality development: An advanced textbook (pp. 361-433). Psychology Press.

Forgas, J. C., \& W., Fiedler, K. (Eds.). (2020). Applications of social psychology: How social psychology can contribute to the solution of real-world problems. Routledge.

Furman, B., \& Ahola, T. (2006). The Twin Star Book: A handbook of solution focused leadership and communication. Helsinki Brief Therapy Institute.

Goldberg, D. P. (1992). GHQ-12. Nfer-Nelson.

Guo, W., \& Wei, J. (2019). Teacher feedback and students' self-regulated learning in mathematics: A study of Chinese secondary students. Asia-Pacific Education Researcher, 28(3), 265-275. https:// doi.org/10.1007/s40299-019-00434-8.

Hamre, B. K., \& Pianta, R. C. (2006). Student-teacher relationships. In G. G. Bear, K. M. Minke, G. G. Bear, \& K. M. Minke (Eds.), Children's needs III: Development, prevention, and intervention (pp. 59-71). National Association of School Psychologists.

Hattie, J. (2009). Visible learning: A synthesis of over 800 meta-analyses relating to achievement. Routledge. 
Hattie, J., \& Timperley, H. (2007). The power of feedback. Review of Educational Research, 77(1), 81-112. https://doi.org/10.3102/003465430298487.

Hattie, J., \& Wollenschläger, M. (2014). A conceptualization of feedback. In H. Ditton, \& A. Müller (Eds.), Feedback und Rückmeldungen. Theoretische Grundlagen, empirische Befunde, praktische Anwendungsfelder (pp. 135-149). Waxmann.

Helmke, A. (2007). Guter Unterricht nur ein Angebot? Friedrich Jahresheft, 2007, 62-65.

Helmke, A., Piskol, K., Pikowsky, B., \& Wagner, W. (2009). Schüler als Experten von Unterricht. Unterrichtsqualität aus Schülerperspektive. Lernende Schule (pp. 98-103).

House, J., Landis, K., \& Umberson, D. (1988). Social relationships and health. Science, 241(4865), 540-545. https://doi.org/10.1126/science.3399889\%JScience.

Ilgen, D. R., Fisher, C. D., \& Taylor, M. S. (1979). Consequences of individual feedback on behavior in organizations. Journal of Applied Psychology, 64(4), 349-371. https://doi.org/10.1037/00219010.64.4.349.

Jennings, P. A., \& Greenberg, M. T. (2009). The prosocial classroom: Teacher social and emotional competence in relation to student and classroom outcomes. Review of Educational Research, 79(1), 491-525. https://doi.org/10.3102/0034654308325693.

Kluger, A. N., \& DeNisi, A. (1996). The effects of feedback interventions on performance: A historical review, a meta-analysis and a preliminary feedback intervention theory. Psychological Bulletin, 119, 254-284. https://doi.org/10.1037/0033-2909.119.2.254.

Kuvaas, B., Buch, R., \& Dysvik, A. (2017). Constructive supervisor feedback is not sufficient: Immediacy and frequency is essential. Human Resource Management, 56(3), 519-531. https:// doi.org/10.1002/hrm.21785.

Leary, M. R., \& Terry, M. L. (2012). Interpersonal aspects of receiving evaluative feedback. In R. M. H. Sutton, Matthew J.; Dougls, Karen M. (Ed.), Feedback: The communication of praise, criticism and advice (pp. 15-28, Language as social action). Peter Lang Publishing Inc.

Mikula, G., Petal, B., \& Tanzer, N. (1990). What people regard as unjust: Types and structures of everyday experiences of injustice. European Journal of Social Psychology, 20(2), 133-149. https://doi.org/10.1002/ejsp.2420200205.

Orsucci, F. F. (2006). The paradigm of complexity in clinical neurocognitive science. The Neuroscientist, 12(5), 390-397. https://doi.org/10.1177/1073858406290266.

Park, J.-A., Johnson, D. A., Moon, K., \& Lee, J. (2019). The interaction effects of frequency and specificity of feedback on work performance. Journal of Organizational Behavior Management, 39(3/4), 164-178. https://doi.org/10.1080/01608061.2019.1632242.

Pianta, R. C., Hamre, B., \& Stuhlman, M. (2003). Relationships between teachers and children. Wiley.

Pianta, R. C., \& Hamre, B. K. (2009). Conceptualization, measurement, and improvement of classroom processes: Standardized observation can leverage capacity. Educational Researcher, 38(2), 109-119. https://doi.org/10.3102/0013189X09332374.

Pianta, R. C., Karen, M., Paro, L., \& Hamre, B. K. (2008). Classroom assessment scoring system (CLASS) manual, pre-K. Brookes Publishing Company.

Pinter, E. B., East, A., \& Thrush, N. (2015). Effects of a video-feedback intervention on teachers' use of praise. Education and Treatment of Children, 38(4), 451-472. https://doi.org/10.1353/etc. 2015.0028.

Ramaprasad, A. (1983). On the definition of feedback. Behavioral Science, 28(1), 4-13. https://doi. org/10.1002/bs.3830280103.

Raudenbush, S. W., \& Jean, M. (2015). To what extent do student perceptions of classroom quality predict teacher value added. In Designing teacher evaluation systems (pp. 170-202). Wiley.

Raufelder, D., Scherber, S., \& Wood, M. A. (2016). The interplay between adolescents' perceptions of teacher-student relationships and their academic self-regulation: Does liking a specific teacher matter? Psychology in the Schools, 53(7), 736-750. https://doi.org/10.1002/pits.21937.

Ryan, R. M., \& Deci, E. L. (2009). Promoting self-determined school engagement: Motivation, learning, and well-being. In K. R. Wenzel, A. Wigfield, K. R. Wenzel, \& A. Wigfield (Eds.), 
Handbook of motivation at school (pp. 171-195, Educational psychology handbook series). Routledge/Taylor \& Francis Group.

Schiepek, G. (2009). Complexity and nonlinear dynamics in psychotherapy. European Review, 17(2), 331-356. https://doi.org/10.1017/S1062798709000763.

Schiepek, G., Aichhorn, W., Gruber, M., Strunk, G., Bachler, E., \& Aas, B. (2016). Real-time monitoring of psychotherapeutic processes: Concept and compliance. Frontiers in Psychology, 7(604). https://doi.org/10.3389/fpsyg.2016.00604.

Schmidt, J.-E. (2018). Verborgene Kräfte im Klassenzimmer wecken: Auswirkungen iterativen Feedbacks der Qualität der Zusammenarbeit zwischen Lehrkräften und ihren Klassen auf die Lehrergesundheit und die Qualität der Zusammenarbeit. Dissertation [Waking hidden power in the classroom: Effects of iterative feedback of the quality of cooperation between teachers and their classes on teacher health and perceived quality of cooperation]. Universität Tübingen, Tübingen.

Seidel, T., \& Shavelson, R. J. (2007). Teaching Effectiveness research in the past decade: The role of theory and research design in disentangling meta-analysis results. Review of Educational Research, 77(4), 454-499. https://doi.org/10.3102/0034654307310317.

Tamara, G., Nancy, L. H., Anastasia, K., \& David, H. (2004). Feedback practices in a sample of children with emotional and/or behavioral difficulties: The relationship between teacher and child perceptions of feedback frequency and the role of child sensitivity. Emotional and Behavioural Difficulties, 9(1), 54-69. https://doi.org/10.1177/1363275204041963.

Umlauft, S., \& Dalbert, C. (2012). Feedback: A justice motive perspective. In R. M. Sutton, M. J. Hornsey, \& K. M. Douglas (Eds.), Feedback: The communication of praise, criticism and advice (pp. 57-71). Lang.

Verschueren, K., \& Koomen, H. M. Y. (2012). Teacher-child relationships from an attachment perspective. Attachment and Human Development, 14(3), 205-211. https://doi.org/10.1080/146 16734.2012.672260.

Wentzel, K. R. (2009). Students' relationships with teachers as motivational contexts. In K. R. Wenzel, A. Wigfield, K. R. Wenzel, \& A. Wigfield (Eds.), Handbook of motivation at school (pp. 301-322, Educational psychology handbook). Routledge/Taylor \& Francis Group.

Jan-Erik Schmidt worked in a residential youth home, in a family-counseling-center, and is school-psychologist at the Center for School-Quality and Teacher-Education in Tübingen (Germany), since 2008. He received his doctoral degree at the University of Tübingen in 2018. His areas of interest are patterns of cooperation in educational settings and change management in complex systems. Jan-Erik is a solution-focused family therapist and board member of the European School Psychology Center for Training.

Caterina Gawrilow is Full Professor for School Psychology at the Eberhard Karls University Tübingen (Germany), since 2013. She studied psychology at the Philipps University Marburg (1997-2002), and received her Ph.D. in 2005 at the University of Konstanz. Caterina Gawrilow also worked as a Postdoc, including at the New York University and the University of Hamburg. Till 2013 she was an Assistant Professor at the Leibniz Institute for Research and Information in Education (DIPF) and the Goethe University Frankfurt. Her research focuses on cognitive, emotional, social, motivational, and neuronal correlates of ADHD, on self-regulation and self-regulation interventions-in experimental and intensive longitudinal designs. 
Open Access This chapter is licensed under the terms of the Creative Commons Attribution 4.0 International License (http://creativecommons.org/licenses/by/4.0/), which permits use, sharing, adaptation, distribution and reproduction in any medium or format, as long as you give appropriate credit to the original author(s) and the source, provide a link to the Creative Commons license and indicate if changes were made.

The images or other third party material in this chapter are included in the chapter's Creative Commons license, unless indicated otherwise in a credit line to the material. If material is not included in the chapter's Creative Commons license and your intended use is not permitted by statutory regulation or exceeds the permitted use, you will need to obtain permission directly from the copyright holder.

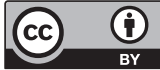

